\title{
EDUCAÇÃO EM SAÚDE E MULHERES IDOSAS: PROMOÇÃO DE CONQUISTAS POLÍTICAS, SOCIAIS E EM SAÚDE
}

\author{
Education in health and elderly women: \\ Promoting of political, social conquests and in health \\ Educación en salud y las muj eres mayores: \\ Promoción de conquistas políticas, sociales y en salud
}

Maria do Livramento Fortes Figueiredo
Benevina Maria Vilar Teixeira Nunes

\author{
Claudete Ferreira de Souza Monteiro \\ Maria Helena Barros Araújo Luz
}

\begin{abstract}
Resumo
Este estudo traz uma abordagem qualitativa sobre a Educação em Saúde e tem como objeto de estudo a descrição dos saberes e práticas adotados pelas mulheres idosas, sujeitos das ações de Educação em Saúde no Programa Terceira Idade em Ação (PTIA), pertencente ao Núcleo de Pesquisa e Extensão Universitária para a Terceira Idade (NUPEUTI) da Universidade Federal do Piauí (UFPI). A investigação teve como objetivos: conhecer saberes e práticas da mulher idosa decorrentes das ações de Educação em Saúde que possibilitem conquistas de autonomia e cidadania; discutir de que forma as integrantes da pesquisa vivenciam os saberes adquiridos por meio das ações de Educação em Saúde que favoreçam conquistas de autonomia e cidadania. Os dados foram agrupados em três categorias de análise. A primeira refere-se à participação da mulher idosa nas políticas públicas, revendo conceitos de cidadania; a segunda categoria abrange o social e a inserção da mulher idosa; e a terceira categoria ressalta a mulher idosa e as questões de saúde. 0 estudo mostra que a mulher idosa é capaz de aprender e agir, conquistando um novo lugar e significado para sociedade, exercendo plenamente sua cidadania.
\end{abstract}

Palavras-chave: Educação em Saúde. Saúde da Mulher. Envelhecimento. Autonomia Pessaoal.

\section{Resumen}

Este estudio trae un acercamiento cualitativo sobre la Educación en la Salud y el he/she tiene como el objeto del estudio la descripción del usted sabe y practica, adoptó por las mayores mujeres sujete de las acciones de Educación en la Salud en el Programa Tercera Edad en Action(PTIA), perteneciendo al Núcleo de Investigación y Extensión de Academical para la Tercera Edad (NUPEUTI) de la Universidad Federal de Piauí (UFPI). La investigación tenía como los objetivos: saber saben y las prácticas de la mayor mujer debido a las acciones de Educación en la Salud que los ellos hacen posibles conquistas de autonomía y ciudadanía; discutir eso forma a los miembros de la investigación ellos los viven usted sabe adquirido a través de las acciones de Educación en la Salud que los ellos favorecen conquistas de autonomía y ciudadanía. Los datos se contuvieron en tres categorías del análisis. El primero se refiere la participación de la mayor mujer en la política pública, revende los conceptos de la ciudadanía; la segunda categoría abraza el social y la inserción de la mayor mujer y la tercera categoría señala la mayor mujer y los asuntos de salud. Las muestras del estudio que la mayor mujer es capaz aprender y actuar, mientras

Keywords: Health Education. Women's Health. Aging. Palabras clave: Educación en Salud. Salud de las Mujeres. Personal Autonomy. 


\section{INTRODUÇÃO}

As questões relativas à Terceira Idade têm crescido em importância ultimamente, uma vez que o envelhecimento da população é um fenômeno global que traz importantes repercussões nos campos social e econômico, especialmente em países em desenvolvimento. Dentre estes se destaca o Brasil, cuja população encontra-se em rápido processo de envelhecimento, podendo seus habitantes chegar em 2025 com 60 anos ou mais, compondo um contingente de 32 milhões de pessoas, o que situará o país em sexto lugar em termos de população idosa. Uma outra constatação dos estudos estatísticos em relação à terceira idade é a existência de um maior número de mulheres em relação ao número de homens ${ }^{1 ; 2}$.

Os estudos demográficos sobre envelhecimento afirmam, freqüentemente, que as disparidades entre os sexos são importantes: as mulheres constituem a maior parte da população mundial idosa. No processo do envelhecimento feminino, os dados mostram que, em 1980, havia em escala mundial, três homens de 65 anos e mais para cada quatro mulheres, relação que se mostra ainda mais forte nos países desenvolvidos, em razão do grande número de homens mortos durante a Segunda Guerra Mundial. Na verdade, quanto mais a idade aumenta, mais as mulheres são numerosas; o envelhecimento passa a ser um fenômeno que se conjuga, antes de tudo, no feminino ${ }^{3}$. Entretanto a vida, a saúde e a doença emergem no processo relacional, que envolvem os diferentes gêneros e faixas etárias. 0 masculino e o feminino não podem ser excludentes, mas compreendidos, pois têm muitas afecções que acometem tanto homens quanto mulheres.

0 envelhecimento da população é um processo natural de qualquer sociedade; mas as pessoas aspiram que isto ocorra de modo que tenham uma vida feliz e saudável. É importante almejar uma melhoria da qualidade de vida para aqueles que já envelheceram ou que estão no processo de envelhecimento. A manutenção da autonomia e cidadania é uma tarefa complexa dessa conquista social ${ }^{3}$.

0 contexto atual, com a baixa prioridade atribuída à Terceira Idade nas políticas públicas (assistenciais, previdenciárias e das ciências e tecnologia), no entanto, não parece favorecer o duplo desafio a ser enfrentado: assegurar serviços de qualidade para os idosos e desenvolver, concomitantemente, recursos humanos de excelência e conhecimento para lidar com o grupo etário que mais cresce no Brasil.

As alterações sociais e patológicas desempenham um papel importante e, em muitas situações, a deflagração desses problemas pode ser atenuada com a adoção de medidas preventivas, que têm como objetivo melhorar a saúde e a qualidade de vida dos idosos. Com o aumento da expectativa de vida, sobretudo para as mulheres, a área de promoção da saúde é mais eficaz, se tratada dentro de uma perspectiva de atendimento global, desempenhando papel importante tanto na prevenção da incapacidade quanto na recuperação da autonomia ${ }^{1}$.

Neste contexto de problematização, o fenômeno que se focaliza no estudo apresenta-se de forma bastante dialética e impregnado de dicotomias entre binômios, tais como: sujeito/objeto, homem/mulher, e entre culturas nacionais, que favorecem interpretações mais flexíveis entre velho/jovem, propiciando deslocamentos da percepção da identidade hegemônica da vida adulta. Estes paradigmas se estabelecem na sociedade contemporânea devido à adoção errônea de uma visão fragmentada do mundo, que precisa ser abandonada com urgência em favor de um novo paradigma baseado na ecologia profunda e na parceria ${ }^{4}$. Dentro destes paradigmas, destaca-se 0 da exclusão da mulher, principalmente da idosa, no que se refere à educação em saúde, considerando-se a ocorrência de perdas significativas que têm influência direta na qualidade de vida da mulher na terceira idade ${ }^{5}$.

0 Programa Terceira Idade em Ação (PTIA) é uma atividade de extensão do Núcleo de Pesquisa da Terceira Idade (NUPEUTI) da Universidade Federal do Piauí (UFPI), no qual são ministrados, a cada semestre, dentre outros, os seguintes cursos: Saúde do Idoso e Orientações Geriátricas para o Envelhecimento Saudável, e nestes cursos têm-se como clientela de alunos, pessoas idosas, com 60 anos ou mais. As turmas são compostas, na sua maioria, por mulheres idosas. Neste grupo constata-se uma melhoria progressiva e contínua das atitudes e práticas destas mulheres no decorrer dos cursos, sendo motivador a formulação de pressupostos que focalizam a Educação em Saúde como o caminho para autonomia e cidadania da mulher na terceira idade.

0 estudo propõe-se a conhecer saberes e práticas de mulheres idosas que participam do grupo de Educação em Saúde do PTIA. A Educação em Saúde permite que as mulheres ultrapassem visões limitadoras e padronizadoras da velhice e, assim, mostrar que o registro de novos conhecimentos é perfeitamente assimilado em qualquer fase da vida6.

Esta perspectiva é coerente com a concepção de que o respeito à autonomia e a dignidade de todo ser humano é um componente ético, não se traduzindo em favores que se possam oferecer aos outros ${ }^{7}$. A autonomia de ação 
está intrinsecamente relacionada com a emancipação, que significa liberdade, mas também a autonomia é capaz de reconhecer os limites pessoais necessários para se obter sucesso nos relacionamentos ${ }^{8}$.

As ações de Educação em Saúde no PTIA contribuem para que o grupo de mulheres idosas desenvolva a consciência da cidadania, capacidade de auto-reflexão e autodeterminação. Assim, o exercício da cidadania em qualquer fase da vida deve ser trabalhado em prol da construção de uma nova sociedade, na qual o interesse do coletivo venha sobrepor ao individual ${ }^{9}$.

Toda esta conscientização visa ao autocuidado, que, de acordo com a teoria de Orem, refere-se à prática de atividades executadas pelo próprio indivíduo, em seu benefício, para manutenção da vida, da saúde e do bem-estar ${ }^{10}$. A Educação em Saúde requer não apenas o treinamento de práticas de autocuidado, mas também o desenvolvimento de conhecimentos, habilidades e atitudes positivas ${ }^{11}$.

Neste sentido, faz-se necessário refletir sobre o conceito de cidadania, que significa ter consciência de direitos e deveres e participar de todas as questões da sociedade. Ou seja, tudo o que acontece no mundo, no país, na cidade, no bairro é da responsabilidade do cidadão, como sujeito de direitos e deveres, com capacidade crítica e reflexiva para exigir as ações públicas que são obrigações do Estado ${ }^{12}$.

Ser mulher é um grande desafio, independentemente da idade, da nacionalidade, do estado civil, econômico, político, social e religioso que ela tenha de origem. $\dot{E}$ comum, na literatura, desde a antiguidade, conferir-se à mulher um status de maior dependência, em que se constata a falta de respeito à sua condição feminina e de cidadã; um processo historicamente institucionalizado que caracteriza um estado de submissão ao homem.

Esta é uma situação que pode ser compreendida tomando por base o gênero, que se configura na construção social baseada em uma diferenciação biológica dos sexos, que se mostra por meio de relações de poder-subordinação, atividades, normas e condutas para homens e mulheres em cada sociedade ${ }^{13}$. Esta construção social vem, ao longo dos anos, colocando para a mulher um papel de submissão e de desvalorização e, quando alcança idades mais avançadas, seu papel se torna ainda mais submisso e dependente.

Contudo, as soluções mais válidas para mudar o rumo dos acontecimentos que estigmatizam a condição feminina devem partir das próprias mulheres, de intervenções multisetoriais, destacando-se as práticas de educação em saúde. Tais práticas permitem a atuação de vários profissionais, sendo marcante a participação da enfermagem nestas ações.

Estudos realizados em Teresina ${ }^{a}$ mostram que a mulher idosa se sente discriminada, principalmente pelo fato de não ter tido acesso à educação e, com isto, à independência socioeconômica. Contraditoriamente, o estudo traz que a mulher idosa piauiense considera-se inovadora, capaz de produzir novos planos e projetos para sair do anonimato mesmo não tendo cursado escola ou universidade; são mulheres que aprendem rápido e possuem saberes vivenciados pela experiência de vida ${ }^{14}$.

Considerando a atuação da enfermagem na docência de um programa multisetorial e interdisciplinar dirigido à terceira idade, em especial às mulheres idosas, tendo em vista estas representarem o maior números de alunos do PTIA, julga-se de fundamental importância e relevância a investigação proposta, que tem como objeto de estudo a descrição dos saberes e práticas, adotados pelas mulheres idosas, sujeitos das ações de Educação em Saúde.

Para nortear o estudo, elaborou-se a seguinte questão norteadora:

Quais os saberes e as práticas são evidenciadas no cotidiano da mulher idosa, são decorrentes das ações de Educação em Saúde?

Para responder a questão norteadora, elaboraramse os seguintes objetivos: conhecer saberes e práticas da mulher idosa decorrentes das ações de Educação em Saúde que possibilitem conquistas de autonomia e cidadania; discutir de que forma as integrantes da pesquisa vivenciam os saberes adquiridos por meio das ações de Educação em Saúde.

\section{METODOLOGIA}

Esta pesquisa utilizou uma abordagem qualitativa por considerá-la adequada para conhecer 0 objeto. 0 grupo participante do curso realizado no PTIA no $1^{0}$ período de 2003, base deste estudo, era constituído de 20 mulheres idosas, e, destas, 10 aceitaram participar da pesquisa.

A técnica de coleta de dados foi a entrevista individual com roteiro semi-estruturado, constituído de três perguntas acerca dos saberes e práticas vivenciadas pelas mulheres idosas nas atividades de educação em saúde e que favoreceram o exercício da cidadania e da autonomia. Os depoimentos foram gravados em fita cassete. A entrevista semi-estruturada valoriza a presença do investigador e oferece perspectivas para que o informante alcance a liberdade e a espontaneidade necessárias, enriquecendo a investigação; isto é, o depoente segue espontaneamente a linha do seu pensamento ${ }^{15}$. 
Para coleta dos depoimentos, foram previamente atendidas as Normas da Res. 196/96 e a aprovação do Comitê de Ética da UFPI. Preservou-se o anonimato dos nomes originais das mulheres, sendo os mesmos substituídos por nomes de flores.

Após leitura minunciosa das transcrições dos depoimentos, os dados foram agrupados em núcleos comuns, formando três categorias de análise. A análise configura-se em olhar profundamente os dados da pesquisa ${ }^{16,17}$, isto é estabelecer compreensão sobre os dados coletados, confirmando ou não os pressupostos estabelecidos no estudo. A análise dos dados de cada categoria buscou apoio temático para interpretação dos depoimentos acerca dos saberes e práticas vivenciadas pelas idosas nas atividades de educação em saúde no PTIA.

\section{RESULTADOS E DISCUSSÃO}

Os dados foram agrupados em três categorias de análise. A primeira refere-se à participação da mulher idosa nas políticas públicas, revendo conceitos de cidadania; a segunda, abrange o social e a inserção da mulher idosa na comunidade; e a terceira categoria ressalta a mulher idosa e as questões de saúde.

\section{Conquistas Políticas}

Os depoimentos mostram que a mulher idosa participante do PTIA descobriu direitos e deveres, que busca a cada dia e em cada lugar ser reconhecida como cidadã, inserida no processo social.

Hoje exijo meus direitos de idosa, no ônibus, na fila do banco, quando vou receber meu dinheiro, mesmo o povo novo reclamando eu passo na frente, porque sei que é meu direito. (Margarida, 82 anos, alfabetizada, classe baixa, viúva, mora com duas filhas, uma delas tem dois filhos).

Aprendi coisas importantes, conheço a Lei do Idoso, sei do Conselho dos Direitos dos Idosos, sei dos Centros de Convivência de Teresina. Agora sei me cuidar e ninguém me engana mais. (Rosa, 64 anos, escolaridade ensino médio, classe baixa, solteira, sem filhos, mora com os sobrinhos).

Estes depoimentos relatam a importância da Educação em Saúde para mulheres idosas, mostrando que a mulher chega à terceira idade sem conhecer seus direitos e sem questioná-los, só o fazendo quando de fato conhece estes direitos, passando a agir sem temor e garantindo seu espaço.

Observa-se também que, a partir do conhecimento dos direitos de cidadã, a mulher idosa adquire auto-estima e, inclusive, passa a se autocuidar, preservando sua conquista tanto de cidadã, como de mulher que possui capacidades para enfrentar desafios e conquistar saberes, pondo cada dia mais em prática seus conhecimentos.

No entanto, a mulher idosa teve sua historicidade marcada pelas questões de gênero que sempre submeteram a mulher a uma condição de submissão, imobilizando-a em uma situação anticidadania, fazendoa passar a vida inteira sem saber reivindicar seus direitos, silenciando e omitindo a violação dos mesmos ${ }^{17}$.

Essa situação de desigualdades é agravada na terceira idade, pelo desrespeito da sociedade com o idoso, principalmente a mulher idosa, que, desde a infância, adolescência e vida adulta, vive constantemente a ameaça e a efetiva violação da cidadania plena, em diferentes aspectos. Além do mais, uma sociedade brasileira direcionada pelo capital tende a valorizar e respeitar aquelas pessoas consideradas em idade produtiva e reprodutiva, e, neste sentido, a mulher idosa é duplamente penalizada, por ser mulher e por ser idosa ${ }^{18}$.

Pelos depoimentos que se enquadraram na categoria de análise das conquistas políticas das mulheres idosas, destaca-se o papel da educação em saúde como um instrumento fundamental por possibilitar a essas mulheres conhecer as leis, seus direitos e deveres, e os diferentes serviços públicos e privados para assistência ao idoso, e estimular a socialização e mobilização das mesmas para reivindicação, participação em entidades e lutas para garantias dos direitos.

Uma das principais estratégias das Universidades para Terceira Idade (UTI) se faz por meio da Educação em Saúde, a qual considera a experiência cotidiana dos atores envolvidos e tem por finalidade a conquista de maior poder e intervenção nas relações sociais que influenciam a qualidade de suas vidas ${ }^{19}$.

\section{Conquistas sociais}

Nesta categoria, a mulher idosa, participante deste estudo retrata as mudanças ocorridas no seu cotidiano após sua inserção em programas de Educação em Saúde do PTIA.

A partir do que aprendi, passei a me cuidar mais, fazer biodança e hidroginástica, me sinto mais solta, mais animada, sou outra pessoa e gostaria de aprender mais. (Jasmim, 68 anos, escolaridade nível médio, classe social alta, viúva).

Estou caminhando, faço hidroginástica e também sou da Legião de Maria. Ajudando os outros estou me ajudando. Melhorei a minha leitura, agora já sei ler jornal, revista, até as bulas dos remédios. (Margarida, 82 anos, alfabetizada, classe baixa, viúva, mora com duas filhas, uma delas tem dois filhos).

As informações e discussões que temos aqui no PTIA nos orientam muito, o relacionamento com os outros, as atividades de criatividade e a troca de experiência nos ajudam demais. (Lírio, 68 anos, escolaridade ensino médio, classe social média alta, casada, mora com o marido e ainda está em atividade - comércio de presentes).

Estes discursos chamam a atenção por que, independentemente da classe social, do estado civil ou mesmo da idade, as mulheres confirmam que 
participar do PTIA nas atividades de Educação em Saúde contribuiu para alcançarem conquistas sociais antes nunca conseguidas. A educação em saúde abre novas perspectivas para uma vida mais saudável ${ }^{19}$, por promover travessia de saberes e a constituição de redes de afeto e solidariedade entre as mulheres idosas participantes.

Analisando as falas das mulheres idosas sujeitos desta ação cidadã de educação em saúde, percebese claramente ser uma estratégia que não fica preza apenas aos aspectos puramente biológicos do binômio saúde/doença, mas vai além ao estimular a socialização e trabalhar de forma reflexiva e critica os direitos e deveres próprios da cidadania.

\section{Conquistas em saúde}

A mulher idosa, ao ser inserida em programas de educação em saúde, percebe-se ainda com potencial para lutar pela sua saúde e, conseqüentemente, pela melhoria de sua qualidade de vida.

Aprendi muito nas leituras dos textos e sigo as orientações. Sei sobre velhice saudável e sobre as doenças, tanto que qualquer sinal de doença eu já peço para o meu filho me levar ao médico. Estou tomando as vacinas e fazendo hidroginástica: acho que agora posso chegar aos 100 anos, com saúde, por que eu me cuido mesmo. Meu filho fica às vezes brigando comigo querendo que eu coma mais porque sou magra, mas eu aprendi que devemos evitar a obesidade. (Orquídea, 82 anos, escolaridade ensino fundamental incompleto, classe social média alta, mora com o filho solteiro de 62 anos).

Ainda tenho problemas de gastrite nervosa e dor na coluna, mas o que eu aprendi na saúde do idoso foi cuidar da minha comida e dos meus exercícios, e isto eu faço. (Copo de Leite, escolaridade ensino fundamental incompleto, classe social baixa, mora com um filho casado).

Eu faço tudo que posso para seguir as orientações que recebi, como cuidado com sal e gordura nos alimentos, caminho pelo menos três vezes por semana e gosto de pegar o sol até ás 9 horas, porque sei que é bom para os ossos; também bebo muita água porque aprendi que é muito bom para nosso organismo. Acho que melhorei em tudo. (Rosa, 64 anos, escolaridade ensino médio, classe baixa, solteira, sem filhos, mora com os sobrinhos).

Assim como estas, as mulheres participantes desta pesquisa relatam conquistas na saúde e as novas maneiras para viver mais, com mais qualidade de vida. Muitas doenças e suas conseqüências são decorrente da falta de uma ação preventiva, principalmente a informação em saúde, que permitirá a prática do autocuidado ${ }^{10}$.

As principais causas de morbimortalidade feminina, na perspectiva latino-americana (depois das idades reprodutivas) são: enfermidades cardiovasculares, erroneamente designadas como "masculinas"; as enfermidades cerebrovasculares, associadas a taxas de mortalidade femininas mais altas que as masculinas; o diabetes melito, de incidência mais freqüente entre as mulheres; osteoporose, oito vezes mais comum entre as mulheres do que entre os homens; estas doenças afetam entre um terço e meio das mulheres pós-menopáusicas. A infecção urinária afeta duas a cinco vezes mais as mulheres que os homens; e a artrite reumática mostra uma incidência três vezes mais alta nas mulheres que nos homens ${ }^{20}$.

Este quadro de morbidade da mulher idosa trabalhado nos aspectos da promoção e prevenção dentro da educação em saúde garantirão uma maior longevidade e uma minimização das conseqüências destas patologias diante das práticas e atitudes adotadas decorrentes da educação em saúde, que por ser uma estratégia cidadã, leva os sujeitos desta ação a uma conscientização e reflexão sobre atitudes que proporcionam mudança de comportamento.

\section{CONSIDERAÇÕES FINAIS}

Por meio das falas das depoentes e da teorização desses achados, evidenciou-se que as conquistas são possíveis e as rupturas necessárias, principalmente nas superações de mitos negativos e preconceitos relacionados com o envelhecimento, tais como: 0 de considerar a mulher idosa incapaz, improdutiva, inútil e com inteligência deteriorada. Estes aspectos foram desmistificados, uma vez que as falas das mulheres sujeitos deste estudo expressaram a sua capacidade de aprender, de agir, de lutar e de modificar situações que dificultariam as possibilidades de serem autônomas e cidadãs.

Estas mulheres deixaram as velhas atitudes voltadas para o passado e encontraram relações satisfatórias no envelhecimento pela inserção social, ao encontrarem sentido para vida, no aprendizado, na autonomia e na cidadania. Isto foi possível investindo-se no cognitivo e no afetivo, pois, quando o idoso se mantém em atividade e pensante, pode continuar a produzir o tempo todo, conservando suas faculdades mentais.

Considera-se, portanto, que os achados desta investigação evidenciaram que a mulher idosa é capaz de aprender e agir, conquistando um novo lugar e significado para sociedade, exercendo plenamente sua cidadania. 


\section{Referências}

1.Veras RP. País jovem com cabelos brancos: a saúde do idoso no Brasil. Rio de Janeiro (RJ): Relume Dumará; 1994.

2. França LH, Soares NE. A importância das relações intergeracionais na quebra de preconceitos sobre a velhice.In: Veras RP, organizadora. Terceira idade: desafios para o terceiro milênio. Rio de Janeiro (RJ): Relume Dumará; 1997. p.192-243.

3. Peixoto C. De volta às aulas ou de como ser estudante aos 60 anos. In: Veras RP, organizador. Terceira idade: desafios para o terceiro milênio. Rio de Janeiro (RJ): Relume Dumará; 1997. p. 192-241.

4. Afonso F. Semeador de idéias. [on line] [citado 22 de junho de 2006]. Disponível em: http//www.Fritjof Capra no Planeta-Nova Era N_1.htm

5.Both A. Gerontologogia: educação e longevidade. Passo Fundo (RS): Imperial; 1999.

6. Masson JM. Atentado a verdade. Rio de Janeiro (RJ): J.Olympio; 1984.

7. Freire P. Pedagogia da autonomia: saberes necessários à prática educativa. Rio de Janeiro (RJ): Paz e Terra; 1998.

8. Giddens A. A transformaçã̃o da intimidade. São Paulo (SP): UNESP; 1993.

9. Bruno MRP. Autonomia e cidadania: caminhos e possibilidades para o ser idoso. [dissertação de mestrado].São Paulo (SP): Pontifície Universidade Católica; 2000.

10. Orem DE. Concepts of practice. $5^{\mathrm{a}}$ ed. New York(USA): Mc Graw-Hill; 1995.

11. Maia TF, Silva LF. 0 pé diabético de clientes e seu autocuidado: a enfermagem na educação em saúde. Esc Anna Nery Rev Enferm 2005 abr: 9(1): 95-102.

\section{Nota}

aPopulação de Idosos de Teresina (PI) é de 44.436 idosos, sendo $52,1 \%$ mulheres e $47,9 \%$ homens ${ }^{11}$.
12. Souza H, Rodriguez C. Ética e cidadania. São Paulo (SP): Moderna; 1994.

13. Rios RR. Gênero, salud y desarrollo: un enfoque en construcción. In: Elza GG. Gênero, mujer y salud em las Américas. (USA): Organização Panamericana de Saúde. Publicação Científica, Washington, 1993; 541: 3-18.

14. Instituto Brasileiro de Geografia e Estatístico-IBGE. Censo demográfico brasileiro. Brasília (DF); 2000.

15.Carvalho MLF. A mulher na terceira idade: significados e sentido para a enfermagem. [disser tação de mestrado]. Rio de Janeiro (RJ): Escola de Enfermagem Anna Nery/UFRJ; 2000.

16. Triviños AMS. Introdução à pesquisa em ciências sociais: a pesquisa qualitativa em educação. São Paulo (SP): Atlas; 1990.

17. Minayo MCS, organizadora. Pesquisa social: teoria, método e criatividade. Petrópolis (RJ): Vozes; 1996.

18. Motta AB. A dimensão de gênero na análise do envelhecimento. In: Ferreira $M$, organizadora. Os poderes e os saberes das mulheres: a construção do gênero. São Luís (MA): EDUFMA/ Núcleo Interdisciplinar de Estudos e Pesquisa: mulher, cidadania e relações de gênero; Salvador (BA): REDOR; 2001.

19. Gomes MQ. Velhice: a busca de novos espaços de sociabilidade. In: Amaral CCG, organizadora. Múltiplas trajetórias: estudos de gênero. $8^{\circ}$ Encontro da REDOR.Fortaleza (CE): REDOR/NEGIF/UFC; 2001.

20. Fajardo ML. A situação de saúde da mulher na América Latina e Caribe: uma análise com a ótica de gênero. Goiânia (G0): OPAS/OMS; 1997.

\section{Sobre as Autoras}

\section{Maria do Livramento Fortes Figueiredo}

Prof. ${ }^{a}$ Dr. ${ }^{a}$ do Departamento de Enfermagem da Universidade Federal do Piauí. Coordenadora do Núcleo de Estudo e Pesquisa sobre Mulher e Relação de Gênero (NEPEM) / (UFPI). Vice-presidente da Associação Brasileira de Enfermagem (ABEn) Seção Piau - Teresina - PI

\section{Claudete Ferreira de Souza Monteiro}

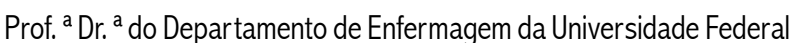
do Piauí. Sub-coordenadora do Núcleo de Estudo e Pesquisa sobre Mulher e Relação de Gênero (NEPEM) / (UFPI). Diretora do Centro de Estudos e Pesquisas (CEPEn) da ABEn - PI - Teresina - PI.

\section{Benevina Maria Vilar Teixeira Nunes}

Prof. ${ }^{a} D r^{a}$ do Departamento de Enfermagem da Universidade Federal do Piauí. Diretora Científica Cultural da ABEn-PI - Teresina - PI.

\section{Maria Helena Barros Araújo Luz}

Prof. ${ }^{a}$ Dr. $^{\text {a }}$ do Departamento de Enfermagem da Universidade Federal do Piauí. Coordenadora do Curso de Doutorado do Pólo da UFPI do Programa de Qualificação Institucional (PQI/CAPES) - Teresina - PI. 